\title{
La alveolización y otras formas de alteración desarrolladas sobre las areniscas del palacio de Revillagigedo de Gijón (Asturias)
}

\author{
LUIS VALDEON, ROSA M. ESBERT Y ROSA M. MARCOS \\ Departamento de Petrología. Facultad de Geología. \\ Universidad de Oviedo
}

\section{$R E S U M E N$}

Se identifican, localizan y estudian las diferentes formas de alteración que se desarrollan sobre las areniscas del Palacio de Revillagigedo de Gijón (Asturias), destacando de forma especial el fenómeno de la alveolización por ser el más ampliamente difundido en este monumento. Se hace una descripción de las morfologías alveolares correlacionándolas con los principales factores que las controlan.

\section{$S U M M A R Y$}

The various forms of alteration presented in the monumental sandstones of the "Palacio de Revillagigedo" (Gijón, Spain) are identified, localized and studied. Among them, the alveolation phenomena (honevcomb erosion) stand aut; the morphologically different alveoles are described and their genesis interpreted.

\section{INTRODUCCION}

Los fenómenos de alteración observados en este monumento gijonés, al igual que tantos otros, son consecuencia de la acción mutua entre las caracteristicas propias de sus piedras de construcción y aquellas propias del medio ambiente en que se ubica. En concreto, el Palacio de Revillagigedo está situado en un medio marítimo-urbano, especialmente agresivo, con elevada humedad ambiental, presencia de sales - principalmente cloruros-, polución y fuertes vientos.

Como consecuencia de ello, las areniscas de Revillagigedo están fuertemente deterioradas, con formas de alteración diversas las cuales se traducen, en última instancia, en una progresiva desagregación o pérdida de cohesión entre los granos minerales que las conforman, llegándose frecuentemente al desprendimiento de los mismos. Este fenómeno de arenización está implícito en la formación y desarrollo de los alveolos y se asocia también a las costras de alteración, que en menor proporción, aparecen en el monumento.

Cabe asímismo destacar la abrasión mecánica que sufren algunos sillares, relacionada directamente con la acción de fuertes vientos, así como la presencia de vegetación y de pátinas de diversa indole.

\section{CARACTERISTICAS PETROFISICAS DE LA PIEDRA DE REVILLAGIGEDO}

Como se viene indicando, la única variedad pétrea utilizada en la construcción del Palacio de Revillagigedo es una arenisca, extraida con toda seguridad de afloramientos del Jurásico detritico que se extiende a lo largo de la costa Este asturiana. 
Se resumen a continuación las características petrofísicas, descritas ampliamente en (1), con el objeto de lograr una mejor comprensión de la naturaleza de este tipo de piedra y su relación con las formas de alteración desarrolladas en el monumento.

Composicionalmente, las areniscas están formadas por granos minerales y matriz arcillosa que actúa como fase ligante. Los granos minerales aparecen en porcentajes que oscilan entre el $80 \%$ y $95 \%$, corresponden fundamentalmente a cuarzo $(71 \%-82 \%)$ y feldespatos $(1,3 \%-8,4)$, apareciendo otros minerales en menor proporción. La cantidad de matriz arcillosa que actúa como fase ligante varia entre $4 \%$ y $20 \%$, siendo la caolinita y la illita las especies minerales presentes.

El tamaño de grano oscila de grueso a muy fino $(0,625 \mathrm{~mm}-0,062 \mathrm{~mm})$, siendo el tamaño medio el de "arena fina", $(0,18 \mathrm{~mm})$.

En cuanto a las propiedades físicas, son de destacar la porosidad comunicada y la absorción capilar por tener una especial significación respecto a la alteración. La porosidad comunicada registra valores bastante elevados, entre $14 \%$ y $23 \%$ y está relacionada con el tamaño medio de grano, grado de heterometría granular y porcentaje de arcillas. La succión capilar muestra también valores significativos aunque dispares, con coeficientes que varian entre 31 y $71 \mathrm{~kg} / \mathrm{m}^{2}$ $\min .0,5(1)$.

\section{LA ALVEOLIZACION: ESPECIAL REFERENCIA A LOS MATERIALES DE REVILLAGIGEDO}

La alveolización es un fenómeno alterológico caracterizado por la formación y desarrollo de huecos o cavidades de diferentes tamaños y morfologías, llamados alveolos, en el seno de las rocas; dicho fenómeno comporta una disgregación superficial del material grano a grano. Los alveolos, sobre todo al principio de su formación, pueden aparecer aislados o bien alineados a lo largo de ciertos horizontes sobre todo en el caso en que los materiales presenten estratificación notoria, (2). Pero además de presentarse de esta manera, se han estudiado abundantes ejemplos donde se desarrollan alveolos en rocas sin ningún tipo de anisotropia estructural, (3).

Aunque la alveolización es muy frecuente en rocas tipo arenisca como es el caso de Revillagigedo, diversos autores la han estudiado en otros tipos sedimentarios, principalmente calcarenitas (4) y (5), así como en todo tipo de rocas plutónicas sobre todo si poseen cristales bien desarrollados, como en el caso de los granitos. También se implanta aunque menos frecuentemente, en gabros, gneis y esquistos, así como en rocas volcánicas: lavas, tobas, etc.

El fenómeno de la alveolización parece debido a una interacción entre factores intrínsecos o de la propia roca y extrinsecos, propios del ambiente. Entre los primeros la composición de la piedra juega un papel importante. Concretamente en varios monumentos edificados con arenisca se ha comprobado que son las variaciones composicionales y de tamaño de grano las que determinan, en parte, la formación de alveolos. Así, en general, en las areniscas de grano fino y matriz arcillosa la desagregación arenosa se limita a desmoronamientos de la piedra asociados a películas superficiales que, en ningún caso, forman alveolos; en otras areniscas, con granulometrias más groseras y más pobres en arcillas, la desagregación arenosa conduce a la formación de alveolos, (6).

En cuanto a los factores extrinsecos, la mayoría de los autores aceptan como hipótesis fundamental para la alveolización el fenómeno de la cristalización de sales en las rocas. Es evidente que, el simple crecimiento de un cristal en las fisuras y poros de una roca produce tensiones locales que afectan a la resistencia de la misma. Si en el crecimiento de dichos cristales hay además fenómenos de hidratación, favorecidos por el aumento en la humedad relativa del aire, el desmoronamiento de las superficies rocosas es aún más rápido. 
La presencia de sulfatos y cloruros en las rocas alveolizadas hace pensar que en dicho fenómeno estas sales juegan un papel fundamental habiéndose visto que la migración selectiva de las mismas viene favorecida por el carácter heterogéneo de la roca, (5).

Pauly (7) estudió experimentalmente los diversos factores que intervienen en la alveolización. Para dicho autor, en el desarrollo de la enfermedad alveolar intervienen las sales solubles e higroscópicas, sulfatos y cloruros principalmente, asi como las variaciones de las condiciones higrométricas alrededor de un valor, dentro de una escala de temperatura determinada. La alveolización se produce cuando es posible el aporte de sales a la roca y cuando las variaciones higrométricas son frecuentes dentro de valores no muy amplios. Ambos parámetros son los que controlan el que las sales se solubilicen y/o precipiten; para ello han de ser "sales muy solubles, de rápida solubilidad e higroscópicas, capaces de intercambiar rápida y frecuentemente vapor de agua con el aire", pág. 78, (7).

En zonas costeras como en el caso de Gijón, donde se emplaza el Palacio, la atmósfera puede estar cargada de estas sales, debido a la alta humedad relativa del aire.

Las sales pueden provenir también directamente de las aguas marinas como se evidencia en la frecuente formación de alveolos en las rocas de los acantilados. Las cavidades son excavadas por las sales procedentes, en gran medida, de las salpicaduras de las olas; cuando el agua se evapora precipitan, pudiendo ser observadas en el interior de las cavidades alveolares.

Sin embargo, se han encontrado piedras alveolizadas en ambientes no marítimos. En estos casos las sales pueden provenir de los componentes minerales de la misma roca o más frecuentemente del suelo. Cuando esto ocurre, los alveolos se localizan preferentemente en las partes inferiores del edificio. Las sales pueden estar disueltas en el agua de lluvia, con lo que la alveolización se puede implantar en lugares alejados de la costa (8).

La climatologia interviene para controlar la frecuencia con que se llevan a cabo las variaciones de humedad y temperatura. El viento actúa como propagador del calor y de la humedad.

La orientación del edificio condiciona la implantación y desarrollo de los alveolos, ya que según sea ésta, los agentes climatológicos, viento, lluvia, insolación, etc., actuarán de forma más o menos contundente.

En Revillagigedo la alveolización se desarrolla de una manera no uniforme, hay bloques más afectados que otros y zonas donde se localiza de manera preferente. En la Fig. 1 se presenta un esquema general del exterior del Palacio y Colegiata en el que se señalan las zonas más alveolizadas; las Figs. 2, 3 y 4 muestran detalles de esta alveolización. Su distribución en el conjunto monumental, asi como las diferentes morfologias con que se manifiesta, se debe, frente a parecidos factores ambientales, a tres causas fundamentales: a las variaciones petrográficas del material rocoso dentro de un mismo tipo litológico; a la orientación de la laminación interna de la roca respecto a la superficie exterior del sillar, y a la situación de los bloques respecto a la orientación del monumento.

Las variaciones petrográficas que influyen en la formación y morfología de los alveolos, se refieren sobre todo a la relación entre la cantidad de matriz arcillosa y la de granos minerales. En el monumento ha podido observarse una gradación entre la cantidad de matriz arcillosa y las diferentes morfologias alveolares. Se ha constatado, a través de la observación de láminas delgadas, que la pérdida de definición de los alveolos está determinada por una mayor concentración de dicha matriz, en detrimento de los granos minerales. En las Figs. 5, 7 y 9 , pueden observarse los casos extremos de esta evolución: En la Fig. 5, se aprecia una alveolización muy desarrollada con alveolos profundos y bien conformados; la lámina delgada correspondiente (Fig. 6), muestra una escasa presencia de matriz entre los granos minerales. En la 


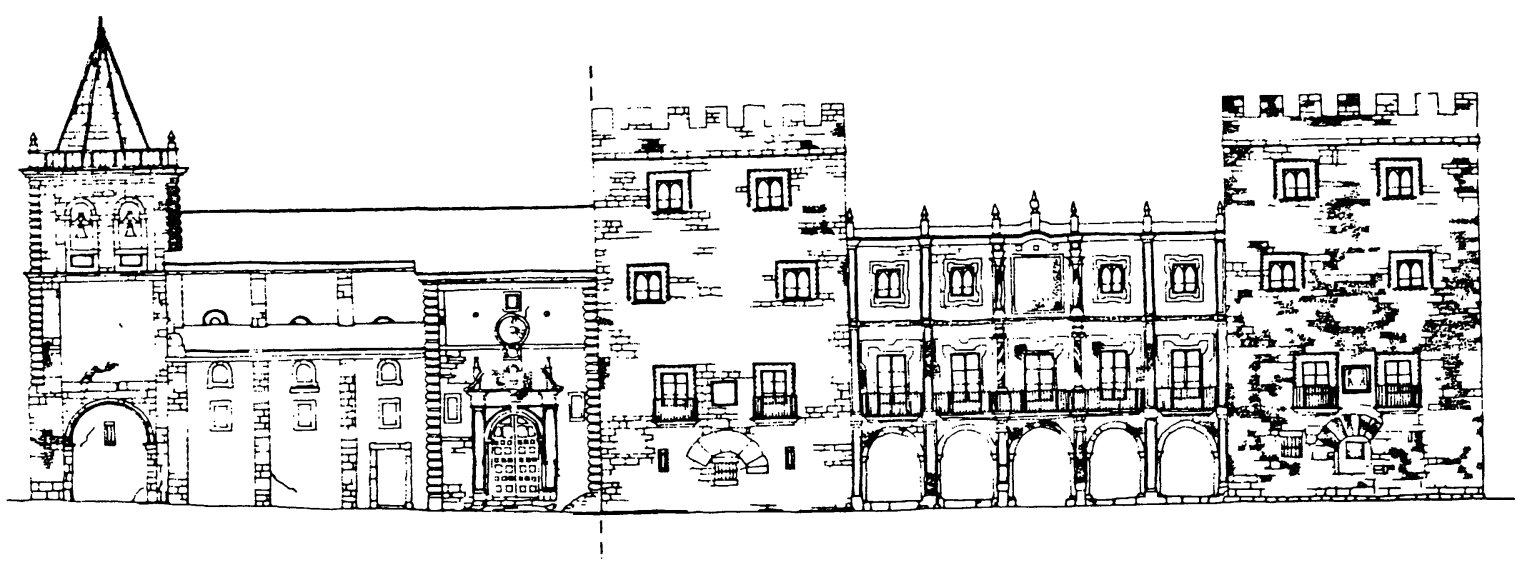

Fig. 1.-Esquema de la fachada principal del Palacio y Colegiata de Revillagigedo (Gijón). En puntos se resaltan las zonas mas alveolizadas.

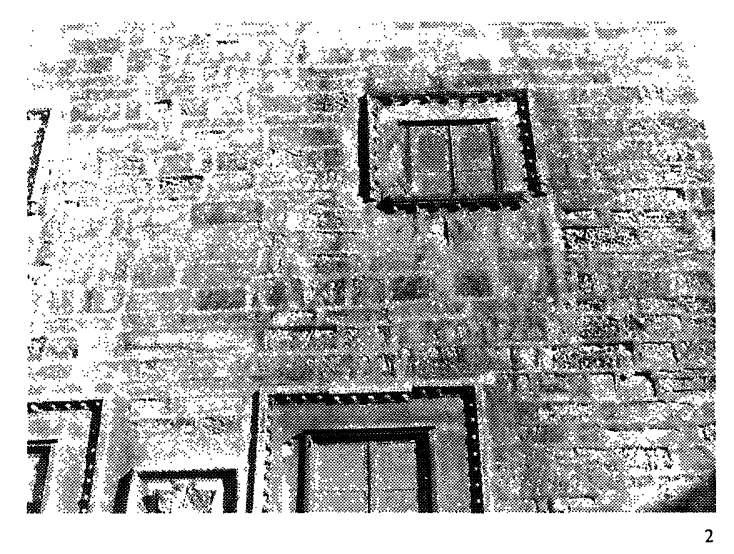

Fig. 7, aparece un sillar con fuertes relieves muy irregulares pero que no llegan a formar verdaderos alveolos; el aumento de matriz entre los granos minerales es bien visible en la lámina delgada correspondiente, (Fig. 8). Por último y como caso extremo un aumento importante del porcentaje de matriz, origina una arenización intensa, pero sin formación de alveolos ni tan siquiera relieves de importancia, (Figs. 9 y 10).
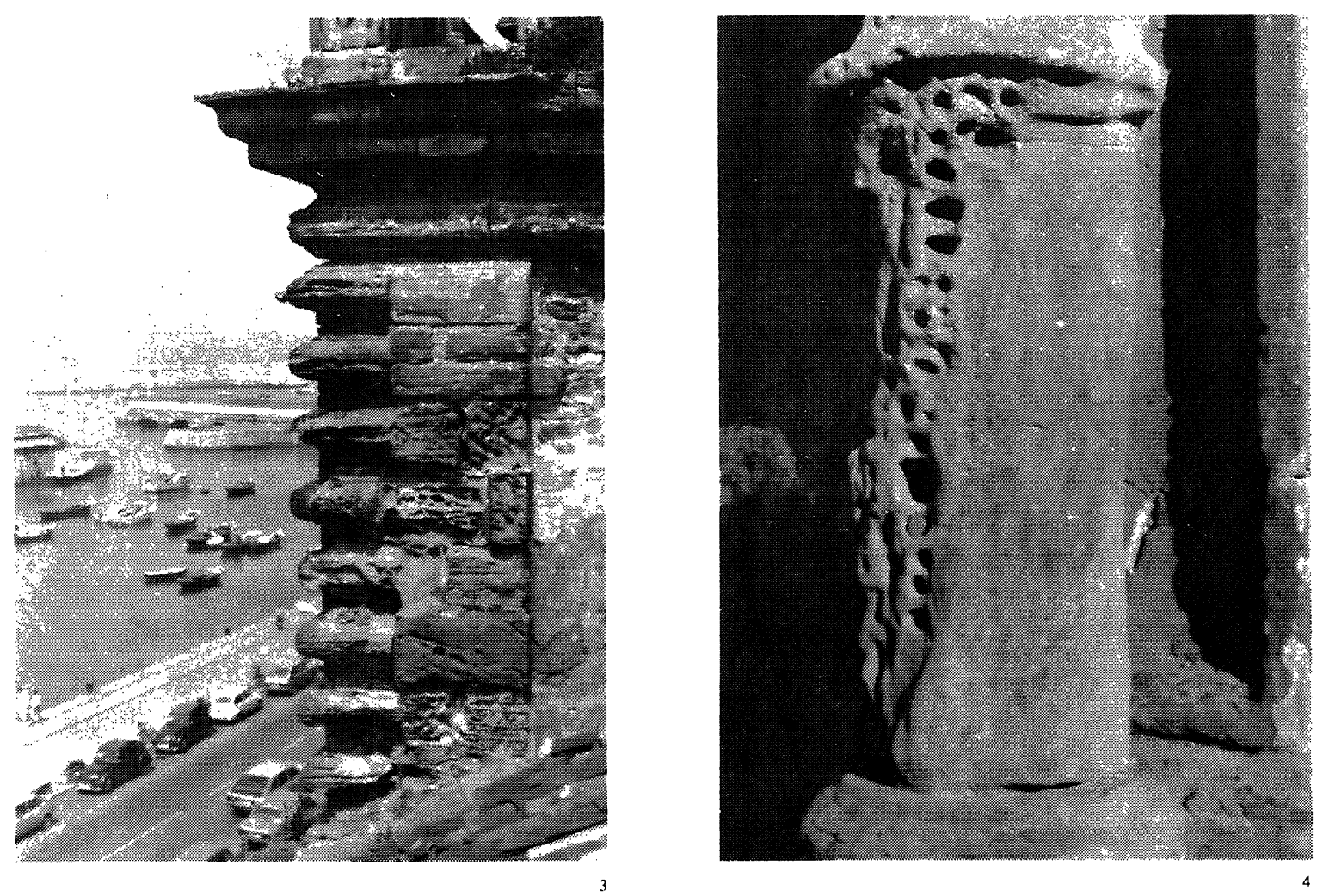

Figs. 2. 3 y 4. Algunos detalles de las zonas alveolizadas correspondientes a: la Torre derecha del Palacio; esquina Sur de la Torre de la Colegiata y una de las columnas de la entrada principal del Palacio. 

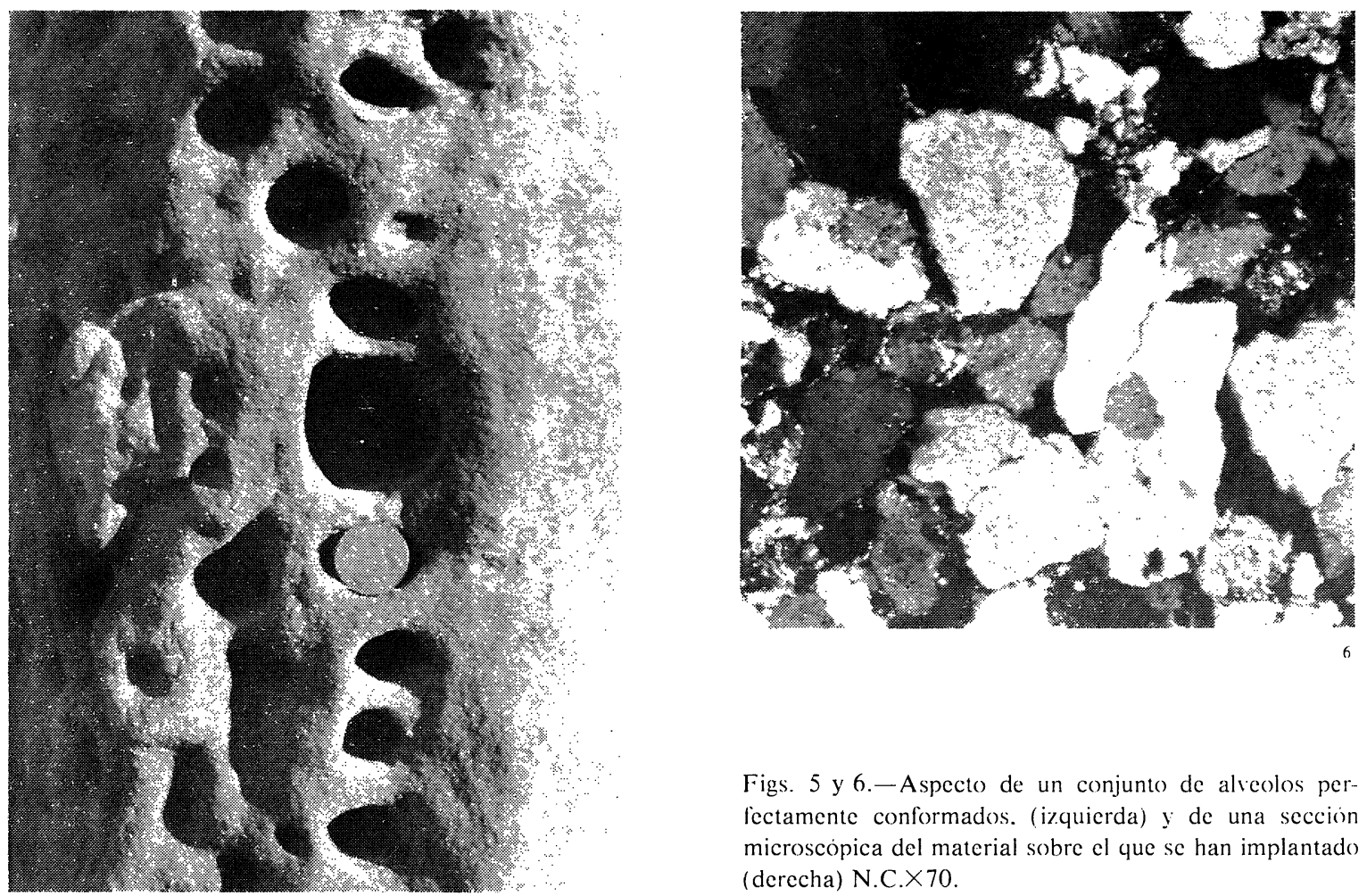

Figs. 5 y 6.-Aspecto de un conjunto de alveolos perfectamente conformados. (izquierda) y de una seccion microscópica del material sobre el que se han implantado (derecha) N.C. $\times 70$.
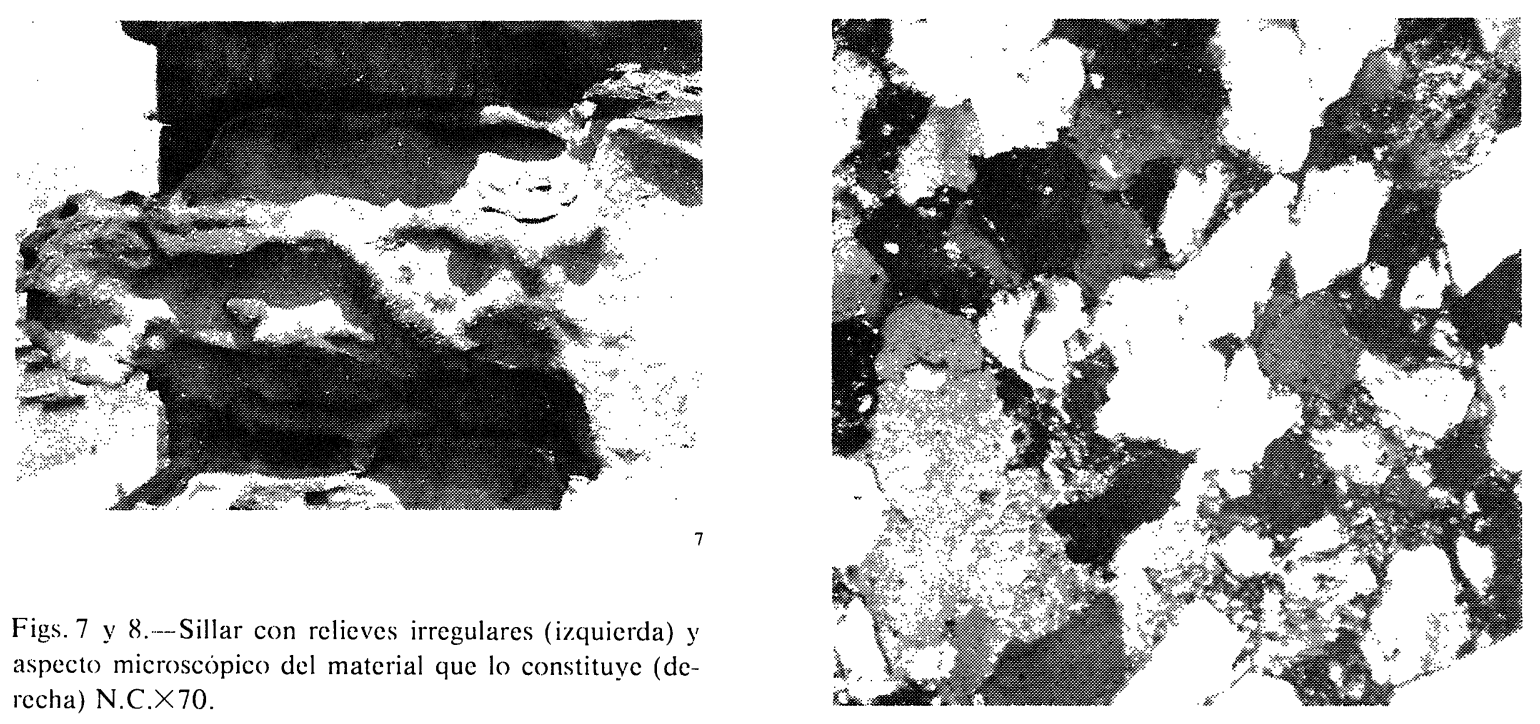

Figs. 7 y 8.--Sillar con relieves irregulares (izquierda) y aspecto microscopico del material que lo constituye (derecha) N.C. $\times 70$.

La orientación de la laminación interna respecto a la superficie del sillar, interviene también en la configuración de la morfología alveolar. Si la laminación es perpendicular a la superficic externa del bloque, los alveolos tienden a alinearse según sus planos de estratificación y a adquirir formas elongadas paralelas a ellos, (Fig. 11). Esto es lógico, ya que no todas las capas tienen la misma composición y la arenización comenzará en los estratos más débiles, formándose al principio pequeñas cavidades que luego se irán agrandando, según los citados planos de estratificación. Si la laminación de la roca es paralela a la superficie del bloque. la formación de alveolos no encuentra planos de debilidad y su desarrollo en profundidad se verá limitado, en algún momento, por capas más resistentes, resultando una morfologia mucho más irregular, con depresiones y protuberancias menos delimitadas que no suelen formar cavidades cerradas, (Fig. 12). 


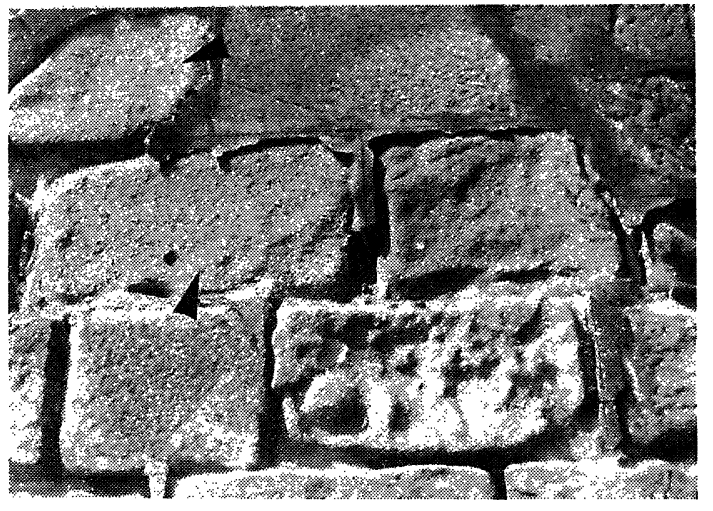

Figs. 9 y 10.-Sillares arenizados. señalados con sendas flechas. (izquierda) y textura microscópica de la arenisca a que pertenecen (derecha). N.C. $\times 70$.

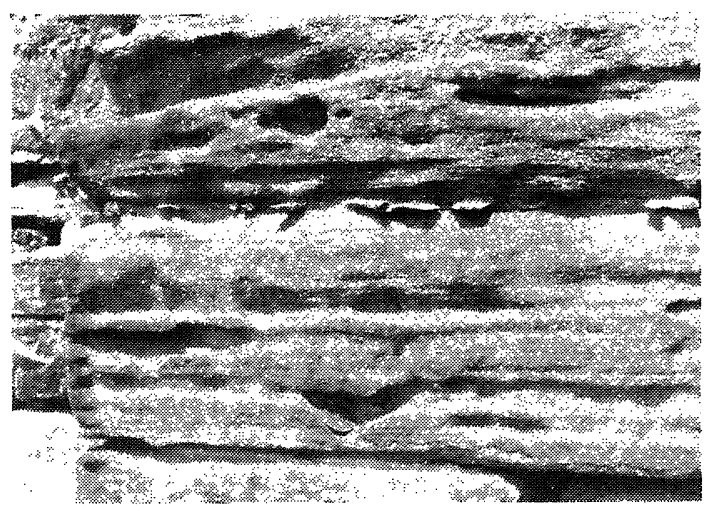

Fig. 11.-.-Alreolos y acanaladuras dispuestos paralela. mente a la laminacion del sillar.

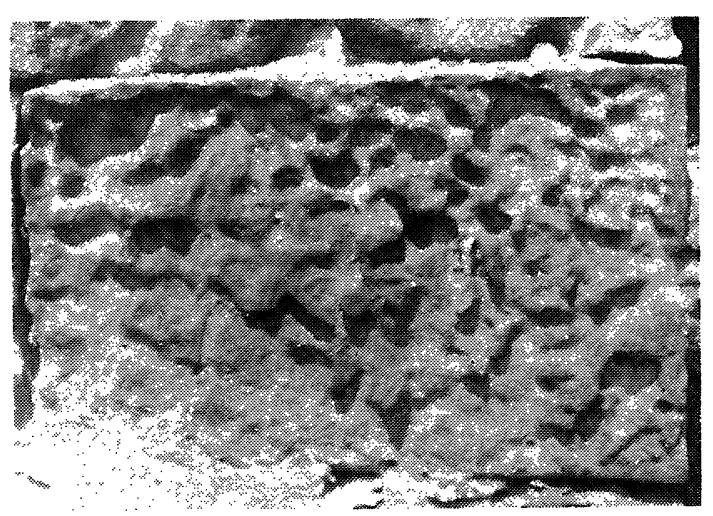

Fig. 12.- Alseolizacion con morfologra irregular debido a que, el sillar, está colocado con la laminación de la piedra paralela a la superficie del bloque.
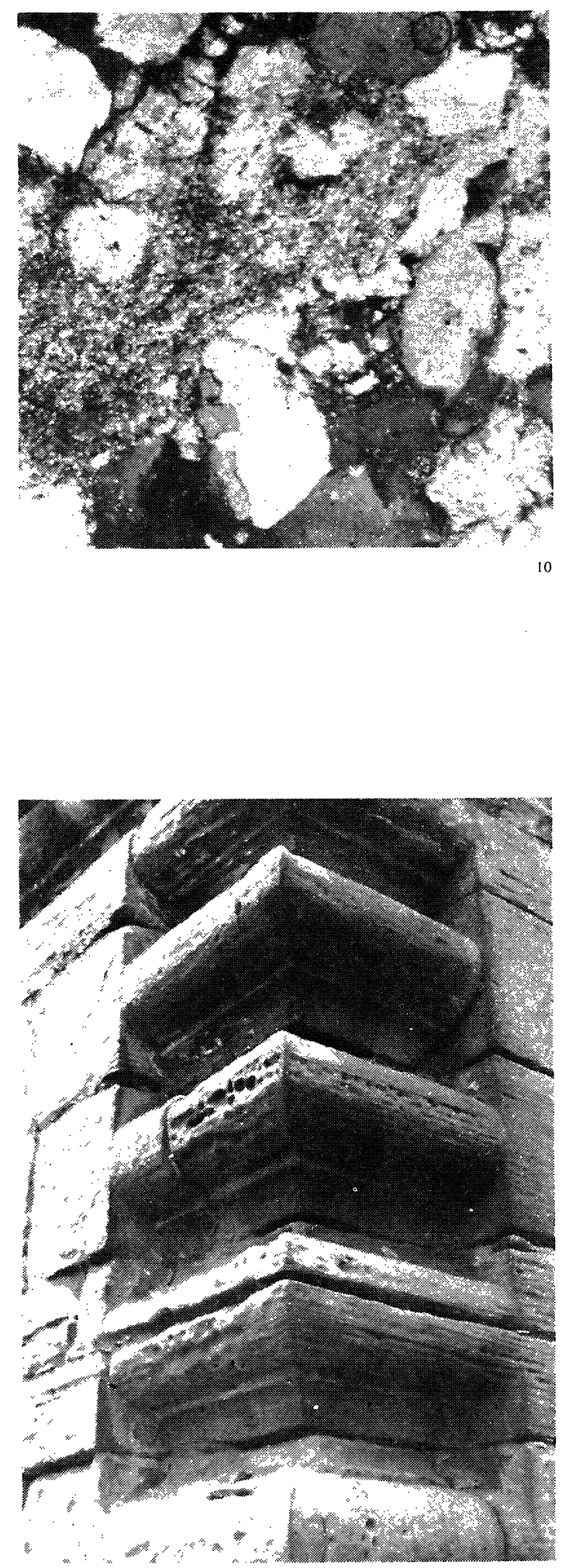

Fig. 13. Detalle de la alteracion de los sillares en una de las esquinas de la Torre de la Colegiata. Hay más alveolos y mejor conformados en los sillares orientados hacia el Sur.

Por otra parte, la situación de los sillares en cada parte del edificio es decisiva puesto que los agentes climatológicos y ambientales, incidirán en mayor o menor grado sobre ellos. Este efecto se constata en la torre de la Colegiata, de planta cuadrada y en cuyas caras se aprecia una 
gradación en la intensidad de la alteración y de la alveolización desde el Sur hacia el Norte; la esquina Sur se halla totalmente afectada por una intensa alveolización que se extiende a la práctica totalidad de los sillares, (Fig. 2), estando la esquina Norte, sin embargo, perfectamente conservada. Este mismo hecho es perfectamente visible en una de las esquinas de la torre donde los sillares orientados más al Sur, muestran una alveolización más intensa, (Fig. 13).

\section{OTRAS FORMAS DE ALTERACION}

Además de la alveolización hay en Revillagigedo otras formas de alteración que obedecen a fenómenos diversos. La abrasión o desgaste de algunos sillares se debe a fenómenos predominantemente mecánicos debido a la acción erosiva de los vientos locales. El predominio de la abrasión mecánica es patente en la portada de la Colegiata.

También se han observado costras en lugares resguardados del edificio, tanto bajo balcones y voladizos, como en sillares de la fachada sur del Palacio, donde se presentan muy desarrolladas, (Fig. 14). El examen de estas costras con microscopio electrónico de barrido, revela la existencia de abundantes cristales de yeso de neoformación, (Fig. 15). La presencia de yeso, en estas areniscas en las que no se ha detectado cemento carbonatado, implica que el ion calcio, al ser ajeno a la roca tiene que provenir, o bien del medio ambiente, o bien de la cal usada como ligante entre los sillares, (6).

Por otra parte en la formación de yeso, la procedencia atmosférica de los compuestos de azufre $\left(\mathrm{SO}_{2}, \mathrm{SO}_{3}, \mathrm{H}_{2} \mathrm{SO}_{4}\right)$ es evidente, sobre todo en un ambiente contaminado como es el de Gijón.

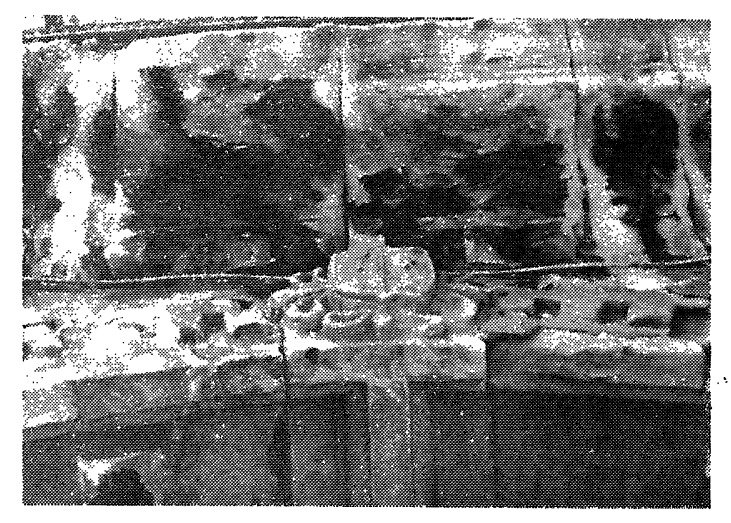

1.ig. 14. Costras. emmugrecidas en su parte externa. en una zona resguardada sobre la puerta principal del Palacio.

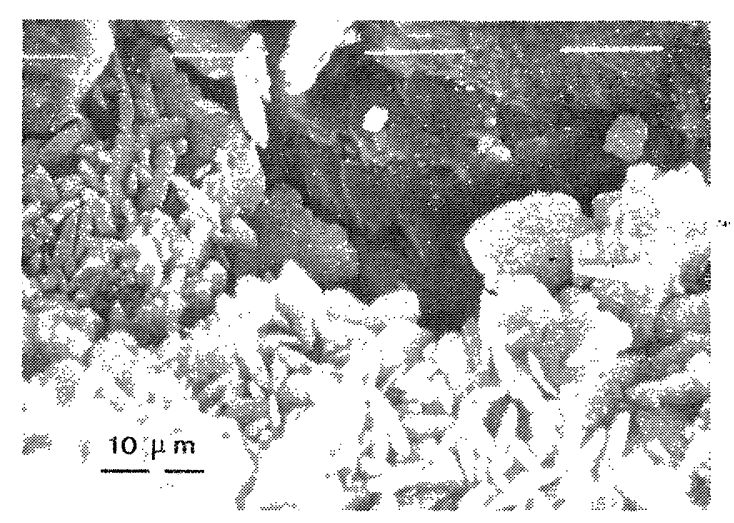

Fig. 15. Detalle de los cristales de geso neoformados en una costra de alteracion. (S.E.M.).

También hay abundantes pátinas de rubefacción, producidas por el lavado y lixiviación de los compuestos de hierro de la roca y de emmugrecimiento, favorecidas por la ascensión capilar del agua del suelo. A diferencia de las costras, cuya formación implica una modificación del sustrato rocoso a nivel composicional y físico, las pátinas suponen solamente una modificación superficial de la roca sin que se produzcan necesariamente fenómenos de alteración. (9).

\section{INCIDENCIA DE LA ORIENTACION DEL MONUMENTO}

Analizados los factores que condicionan la morfologia alveolar, asi como los mecanismos que controlan tanto su desarrollo. como el de las otras formas de alteracion, es interesante resaltar algunos aspectos que atañen a la implantación de las mismas on este conjunto monumental. Así. 
las diferentes formas alterológicas pueden coexistir en zonas muy próximas del edificio o tener localizaciones preferentes de acuerdo con condicionantes ambientales o metereológicos.

Por ejemplo, el predominio de la abrasión mecánica en la Portada de la Colegiata con orientación al Noroeste, indica que en esta dirección han actuado vientos fuertes, por lo tanto no es de esperar y de hecho asi ocurre, que pueda haber costras en esa Portada, ya que éstas necesitan de ambientes resguardados de lluvia y viento para desarrollarse.

La fachada principal del Palacio con orientación Sur, muestra varias formas de alteración: arenización, abundante alveolización y costras. Esta coexistencia de formas cuyo denominador común es el fenómeno de la cristalización de sales presupone, para su formación y desarrollo, un ambiente resguardado, no abatido por vientos. En efecto, este hecho se pone en evidencia si se tiene en cuenta que los vientos predominantes en Gijón son el N.E. y el S.W. (10).

\section{AGRADECIMIENTO}

A la Comisión Asesora de Investigación Cientifica y Técnica (Ministerio de Educación y Ciencia) por la financiación de la presente investigación (Proyectos 4446/79 y 2573/83).

\section{B I B L I O G R A F I A}

(1) ESBERT, R. M.; L. VALDEON, (1984): "Estudio petrofísico y alterológico de las areniscas del Palacio de Revillagigedo de Gijon (Asturias)". Materiales de Construcción. Vol. 34. n. ${ }^{194}$, Abril-Mayo-Junio 1984, pp. 61-72.

(2) JEANNETE. D., (1980): "Les grès du Chateau du Landsberg: exemple d'evolution des "Gres Vosguiens" en milieu rural”. Sci. Géol. Bull., 33, 2. Estrasburgo, pp. 111-118.

(3) MUSTOE, G.E., (1982): "The origin of honeycomb wheathering”. Geological Society of American Bulletin, v. 93, pp. 108-115.

(4) ROSSI-MANARESI, R.; C. GHEZZO, (1978): "The biocalcarenite of the Agrigento Greek Temples: Causes of the alteration and cffectiveness of conservations treatments". Proc. of the Int. Symp. on Deterioration and Protection of Stone Monuments, Paris, June, 1978, T-III, 7.9., $31 \mathrm{p}$.

(5) CUTTANO, M.: P. MASTRONARDI: R. ROSSI-MANARESI, (1981): "Alveolar wheathering of the "tuff" of Matera. mechanism of deterioration and effectiveness of preservation treatments". The Conservation of Stone II, Bolonia. pp. 355-377.

(6) JEANNETTE, D., (1981): "Modifications superficielles de grès en auvre dans des monuments alsaciens". Sci. Géol. Bull., 34. 1. Estrasburgo. pp. 37-46.

(7) PAULY. J. P., (1975): “Maladie alveolaire, conditions de formation et d'evolution". The Conservation of Stone, I, Bolonia, pp. 55-88.

(8) PAULY, J. P. (1976): "Le role des chlorures dans les maladies alveolaire et descamante", Proc. of the 2nd. Int. Symp. on the Deterioration of Building Stones, Atenas, pp. 79-81.

(9) ESBERT, R. M.; R. M. MARCOS, (1983): "Las piedras de la Catedral de Oviedo y su Deterioracion". Publ. Colegio Oficial de Aparejadores y Arquitectos Técnicos de Asturias, Oviedo, 147 p.

(10) MATEO, P. (1975): “El clima de Gijón”. Memorias Servicio Metereológico Nacional. Ministerio del Aire, Dirección General de Vuelo. Publi., Serie A C, n. 25. 